\title{
Thermal decomposition of monosaccharides derivatives applied in ceramic gelcasting process investigated by the coupled DTA/TG/MS analysis
}

\author{
Paulina Bednarek • Mikolaj Szafran
}

Bretsznajder Special Chapter

(C) The Author(s) 2012. This article is published with open access at Springerlink.com

\begin{abstract}
The paper reports the decomposition of saccharides derivatives in comparison to commercial substances during the process of binder removal from ceramic samples. The saccharides derivatives are polymers synthesized from glucose and fructose with acryloyl group in the sugar molecule. The synthesized compounds played the role of binder in the shaping of ceramic powders by gelcasting method. The method belongs to colloidal processes and allows to produce ceramic elements of complicated geometry. As ceramic powder $\mathrm{Al}_{2} \mathrm{O}_{3}$ was used. The thermal analysis have been done on apparatus coupled with mass spectrometer. MS analysis showed what types of gasses are released to the atmosphere during the thermal decomposition of polymers. The obtained results showed important differences in decomposition of polymers obtained from commercial acrylamide, 2-hydroxyethyl acrylate and $N, N^{\prime}$-methylenebisacrylamide in comparison to synthesized glucose and fructose derivatives. The measurements allowed to establish the sintering program of the green ceramic samples and evaluate whether harmful $\mathrm{NO}_{x}$ gases are released to the atmosphere.
\end{abstract}

Keywords Gelcasting - Saccharides derivatives · Thermal decomposition - Mass spectrometer . Nitrogen dioxide

P. Bednarek $(\bowtie) \cdot$ M. Szafran

Faculty of Chemistry, Warsaw University of Technology,

3 Noakowskiego St., 00-664 Warsaw, Poland

e-mail: bednarek@ch.pw.edu.pl

\section{Introduction}

Advanced ceramic materials are used in variety industries, especially in optoelectronics, metallurgy, medicine, and space industry due to their high thermal resistance, hardness and other unique properties. The key stages in the fabrication of ceramics are shaping of powders and sintering. There are many shaping techniques in ceramic technology but most of them have important disadvantages such as nonhomogeneity of powder compacts, size and geometry limit of produced element, use of high pressure, long binder burnout and high costs. In order to overcome these limitations some novel shaping technologies have been recently developed on the basis of colloidal processing of ceramic powders, for example gelcasting [1-3], monomer based sol-gel, electrophoretic deposition $[4,5]$ or direct coagulation casting $[6,7]$. Gelcasting allows obtaining high-quality, complex-shaped ceramic elements by means of an in situ polymerization, through which a macromolecular network is created to hold ceramic particles together (Fig. 1). Gelcasting requires effectively working processing agents like deflocculants and organic monomers which can insure advantageous microstructure, good mechanical properties of green bodies and facilitate the processing route.

The processing agents used in gelcasting, especially organic monomers should be low-toxic and follow the recent "green chemistry" trend. The less toxic and the less harmful for the environment they are, the more attractive they are to apply. One of the first water-soluble monomers used in gelcasting was acrylamide. It insures good mechanical properties of obtained elements, nevertheless it is classified as strong neurotoxin and probably carcinogenic substance [8]. Second, it contains a nitrogen atom in a molecule, so during binder decomposition nitrogen oxides are released into the atmosphere what is harmful for the environment. 
Fig. 1 The schematic image of gelcasting process

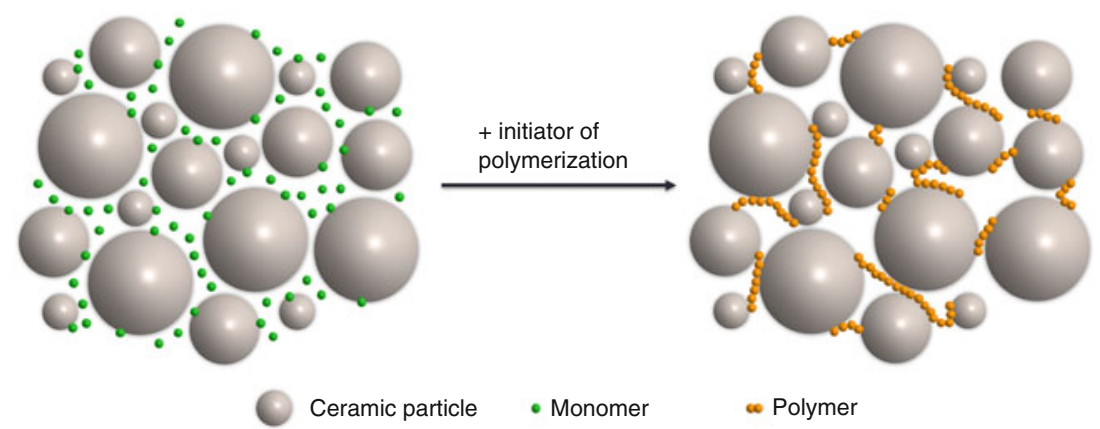

Later on researchers began to use substances which do not contain the nitrogen atom in the molecule such as 2-hydroxyethyl acrylate [9]. It should be also mentioned that both acrylamide and 2-hydroxyethyl acrylate have to be used together with so called cross-linking agent (e.g. $N, N^{\prime}$-methylenebisacrylamide) which allows to form cross-linked polymeric networks instead of linear chains $[10,11]$.

The use of saccharides in the ceramic technology for considerable scale seems to be a new trend, but it has already been intensively developed by many researchers [12-14]. Mono- and disaccharides, as processing agents, have many advantages in comparison to commercially available acrylic monomers. They are non-toxic, watersoluble, inexpensive and renewable substances. Moreover, derivatives of monosaccharides can be used as organic monomers in gelcasting process, they can be easily removed from samples during binder decomposition process and they have the positive influence on mechanical strength of green bodies [15].

In order to overcome mentioned limitations low-toxic monomers based on saccharides were synthesized by authors and applied in gelcasting. The synthesis of these compounds have been elaborated by authors and described elsewhere as well as the properties of obtained ceramic parts [15-17]. Saccharides have many hydroxyl groups in a molecule; thereby the cross-linked polymer network can be created by forming hydrogen bonds between polymeric chains. As a result the use of external cross-linking agent as in the case of acrylamide is not necessary and the amount of organic additives needed in the suspension is reduced, thus the whole process becomes less expensive.

The polymer plays the role of binder in ceramic green body that is why it must be removed from the element to achieve fully densified, polycrystalline ceramic body [18]. The polymer is removed by its thermal decomposition during debinding process. The selection of appropriate heating program is significant in obtaining nonporous samples [19]. During polymer removal too fast heating rate (e.g. over $5{ }^{\circ} \mathrm{C} / \mathrm{min}$ ) can result in obtaining porous structure due to accumulation of gases in a sample. The best tool which allows to determine the thermal decomposition of organic substances in ceramic samples and the proper heating program seems to be DTA/TG measurements [20]. The important information from thermal analysis is the temperature at which decomposition of organics ends. The heating program of ceramic green bodies is then so matched that the slower heating rate is till the end temperature of decomposition. Next the heating rate can be increased. Nevertheless, the heating rate till the final temperature of sintering has also the important influence on the properties of sintered elements [21,22]. What is more, the coupling of DTA apparatus with mass spectrometer allows observing types of gases released to the atmosphere during decomposition of polymers. Similarly, during thermal decomposition of any other substances with the use of coupled mass spectrometer it was possible to examine gaseous products [23-25]. This is the very important issue concerning the rules of "green chemistry."

The paper reports the decomposition of monosaccharides derivatives such as 3-O-acryloyl-D-glucose and 1-Oacryloyl-D-fructose in comparison to commercial substances commonly used in gelcasting (acrylamide and 2-hydroxyethyl acrylate) during the process of binder removal from ceramic samples. The samples were composed of alumina powder with selected monomers and obtained by gelcasting shaping technique. The mentioned monosaccharides derivatives have been chosen due to their positive influence on the properties of both ceramic suspensions and green bodies, as described elsewhere [15]. DTA/TG/MS analysis allows to recognize decomposition products of glucose and fructose derivatives which is important concerning practical application of these monomers and environmental issues.

\section{Materials and experimental procedure}

The research has been carried out on alumina powder $\alpha$ $\mathrm{Al}_{2} \mathrm{O}_{3}$ Nabalox 713-10 (Nabaltec, Germany) of mean particle size $D_{50}=0.70 \mu \mathrm{m}$ and selected organic monomers which played the role of binder in the gelcasting shaping process. As mentioned before, two monomers were 
synthesized by authors as derivatives of monosaccharides, namely 3-O-acryloyl-D-glucose and 1- $O$-acryloyl-D-fructose. The next two monomers were commercially available: acrylamide (Fluka, $\geq 98 \%$ ) and 2-hydroxyethyl acrylate (Fluka, $>97 \%$ ). The chemical formulas of applied monomers are shown in Fig. 2a-d. 3-O-acryloyl-D-glucose and 1-O-acryloyl-D-fructose were used at $50 \%$ aqueous solutions, whereas 2-hydroxyethyl acrylate, $N, N^{\prime}$-methylenebisacrylamide, and acrylamide as pure anhydrous substances. It is necessary to use saccharides derivatives as aqueous solutions because they are resinous substances, therefore the application of pure monomers to the ceramic suspension would be troublesome. 2-Hydroxyethyl acrylate is a liquid of a low viscosity, while acrylamide and $N, N^{\prime}$ methylenebisacrylamide are solid.

Alumina aqueous suspensions containing $50 \mathrm{vol} \%$ ( $80 \mathrm{wt} \%$ ) of ceramic powder were prepared in redistilled water in planetary ball mill Retsch PM 100 for 90 min with a speed $300 \mathrm{rpm}$. The supporting substances which allowed to achieve a stable ceramic suspension and conduct in situ polymerization are described below. The mixture of diammonium hydrogen citrate (POCh Poland, puriss) and citric acid (Sigma-Aldrich, $\geq 99.5 \%$ ) were used as dispersants in the amount of $0.25 \mathrm{wt} \%$ with respect to (wrt) the amount of alumina powder. $N, N, N^{\prime}, N^{\prime}$-tetramethylethylenediamine (Fluka, $>98 \%)$ played the role of activator $(0.03 \mathrm{wt} \% \mathrm{wrt}$ alumina powder) and ammonium persulfate (Aldrich, $\geq 98 \%)$ was the initiator of polymerization $(0.05 \mathrm{wt} \% \mathrm{wrt}$ alumina powder). In the typical gelcasting process conducted by authors the amount of monomer added to the ceramic suspension was $3 \mathrm{wt} \%$ wrt ceramic powder. This amount of powder insures enough high mechanical strength of green bodies. In this research the amount of only one monomer 1-O-acryloyl-D-fructose was $3 \mathrm{wt} \%$ to present the results for a typical slurry composition. The rest binders were used in the amount of $20 \mathrm{wt} \%$ wrt ceramic powder to precisely examine the type of gases released during thermal decomposition of polymers. Due to the fact that the amount of specimen taken to the measurement was about $0.2 \mathrm{~g}$ and it came from ceramic green body which volume was $20 \mathrm{~cm}^{3}$, it is necessary to increase the amount of organics in ceramic matrix. Otherwise in $0.2 \mathrm{~g}$ of sample taken to analysis the amount of organics could be insufficient.

In the case of the monomer 2-hydroxyethyl acrylate, additionally $N, N^{\prime}$-methylenebisacrylamide (Sigma-Aldrich, $99 \%$ ) was used as external cross-linking agent (Fig. 2e). The cross-linking agent is a typical substance used together with acrylic monomers such as acrylamide and 2-hydroxyethyl acrylate in the gelcasting to provide high mechanical strength of obtained ceramic green bodies. In this research 2-hydroxyethyl acrylate and $N, N^{\prime}$-methylenebisacrylamide were used together in the amount of $10 \mathrm{wt} \%$ wrt alumina powder each, which results in $20 \mathrm{wt} \%$ of organics in the sample, just as for 3-O-acryloyl-D-glucose and acrylamide.

The prepared ceramic suspensions were then cast into identical plastic molds. The slurries with applied monomers were able to gelate at room temperature. After thick gelled bodies were obtained, specimens were unmolded and dried for $24 \mathrm{~h}$ at $35^{\circ} \mathrm{C}$. Then thermal analysis of ceramic green bodies was performed.

DTA/TG measurements were carried out by using Netzsch STA 449C coupled with Quadrupole Mass Spectrometer Netzsch QMS 403C. The heating rate was $5{ }^{\circ} \mathrm{C} / \mathrm{min}$, the final temperature was $1,000{ }^{\circ} \mathrm{C}$. The measurements were performed in the constant flow of two gases: argon- $10 \mathrm{ml} /$ min (protective gas) and synthetic air $\left(75: 25 \quad \mathrm{~N}_{2}: \mathrm{O}_{2}\right)$ $40 \mathrm{ml} / \mathrm{min}$. The sintering process of ceramic samples obtained by gel casting was then conducted in Carbolite furnace in air. The heating programs have been chosen after thermal analysis as described in "Results and discussion".

\section{Results and discussion}

The obtained results gave two types of information. The TG/DTA measurements showed the characteristics of
Fig. 2 Chemical formulas of substances used in the research: a 3- $O$-acryloyl-D-glucose, b 1 - $O$-acryloyl-D-fructose, c acrylamide, d 2-hydroxyethyl acrylate, e $N, N^{\prime}-$ methylenebisacrylamide (a)

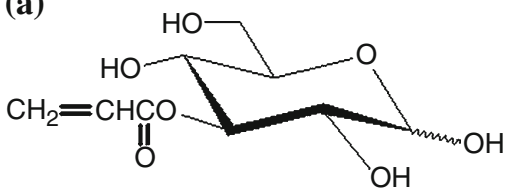

(b)

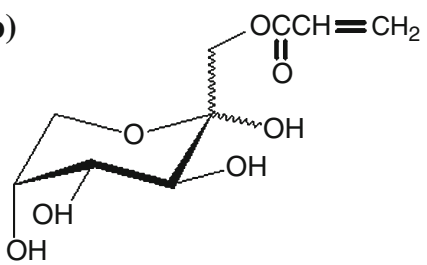

(d)<smiles>C=CC(=O)OCCO</smiles>

(c)<smiles>C=CC(N)=O</smiles>

(e)<smiles>C=CC(=O)NCNC(=O)C=C</smiles> 
polymers decomposition and allowed to evaluate the suitable heating program for sintering of green ceramic samples. MS analysis showed what types of gasses are released to the atmosphere during this thermal decomposition of polymers. These information are essential when environmental aspects are taken into account.

Table 1 summarizes the mass-to-charge ratio $\mathrm{m} / \mathrm{z}$ for gases analyzed during the research. Value $100 \%$ corresponds to the main $\mathrm{m} / \mathrm{z}$ value characteristic for a certain compound in the mass spectrum. The rest of the numbers show intensities of other characteristic peaks in the mass spectrum related to the main peak. For example two peaks of argon occur in the mass spectrum, the first one of $\mathrm{m} / \mathrm{z}$ value 40 and the second one of $\mathrm{m} / \mathrm{z}$ value 20 which has five times lower intensity than peak 40 . The values in Table 1 comes from the database available in the mass spectrometer Netzsch QMS 403C.

The gases $\mathrm{Ar}, \mathrm{O}_{2}$ and $\mathrm{N}_{2}$ were measuring gases which, as had been mentioned before, flew through the apparatus during the entire measurement. They were registered by MS which showed the signals at $m / z$ values $14,16,20,28$, 32, and 40. The course of these lines is presented in Fig. 3, which shows DTA/TG curves for samples prepared from $\mathrm{Al}_{2} \mathrm{O}_{3}$ with $3 \mathrm{wt} \%$ of monomer 1-O-acryloyl-D-fructose synthesized by authors. One can see that the intensities of these signals are much higher than the intensities of gasses generated during the decomposition of analyzed substance, for example $\mathrm{H}_{2} \mathrm{O}$ and $\mathrm{CO}_{2}(\mathrm{~m} / z$ values 18 and 44 respectively), which are almost not visible at Fig. 3 on this scale. Nevertheless, the measurements could be carried out in other atmospheres, for example only in argon or in reductive atmosphere of hydrogen etc. The flow of gases can be changed as well. For example, if the measurements are performed only in argon, then the observed in the background $\mathrm{m} / \mathrm{z}$ values will be 20 and 40 . The conditions of measurements can be selected individually for every sample and as can be seen from Fig. 3 and Table 1 this fact affects what type of gases released during analysis can be identified, taking into account the atmosphere of measurement. In these research, the selected atmosphere was air, because ceramics from $\mathrm{Al}_{2} \mathrm{O}_{3}$ is mostly sintered in air.

According to Fig. 3, the TG/DTG curves indicate that the process of thermal decomposition of polymer formed from 1-O-acryloyl-D-fructose finished at ca. $520{ }^{\circ} \mathrm{C}$, therefore the next results of DTA/MS measurements are shown in Fig. 4 until temperature $620^{\circ} \mathrm{C}$. The similar dependence was observed for all other samples, that is why the results in Figs. 5, 6, and 7 are shown in temperature range $35-680{ }^{\circ} \mathrm{C}$.

Figure 4 shows DTA/TG curves and signals from coupled mass spectrometer MS for sample prepared by gelcasting and composed of $\mathrm{Al}_{2} \mathrm{O}_{3}$ with $3 \mathrm{wt} \%$ of monomer 1-O-acryloyl-D-fructose. The measurement indicates that the total loss of water and decomposition of organic additives occur until ca. $520{ }^{\circ} \mathrm{C}$. The total weight loss is $2.5 \%$ according to TG curve, which corresponds to the moisture and polymer content. This value does not match exactly the amount of monomer added to the ceramic suspension; however as explained before, the analysis was performed for a sample of $\sim 0.2 \mathrm{~g}$. This means that in this volume of the sample the amount of binder may be lower than $3 \mathrm{wt} \%$. On DTA curve two peaks are visible at temperatures 98 and $158{ }^{\circ} \mathrm{C}$ which corresponds to the loss of free and bounded water, respectively. According to TG and DTG curves the loss of water ends at ca. $200{ }^{\circ} \mathrm{C}$. This is confirmed by the presence of to two curves from MS of $\mathrm{m} / \mathrm{z}$ values 17 and 18 , which are the characteristic MS values for $\mathrm{H}_{2} \mathrm{O}$. According to the data in Table 1, the intensity of peak 17 should equal $23 \%$ of the intensity of

Table 1 Distinctive relative intensities of $\mathrm{m} / \mathrm{z}$ values of analyzed gasses according to database available in the mass spectrometer Netzsch QMS 403C

\begin{tabular}{|c|c|c|c|c|c|c|c|c|c|}
\hline $\mathrm{m} / \mathrm{z}$ & $\mathrm{Ar}$ & $\mathrm{O}_{2}$ & $\mathrm{~N}_{2}$ & $\mathrm{CO}$ & $\mathrm{CO}_{2}$ & $\mathrm{H}_{2} \mathrm{O}$ & $\mathrm{N}_{2} \mathrm{O}$ & NO & $\mathrm{NO}_{2}$ \\
\hline 12 & - & - & - & $4.5 \%$ & $6.0 \%$ & - & - & - & - \\
\hline 14 & - & - & $7.2 \%$ & - & - & - & $12.9 \%$ & $7.5 \%$ & $9.6 \%$ \\
\hline 15 & - & - & - & - & - & - & - & $2.4 \%$ & - \\
\hline 16 & - & $11.4 \%$ & - & - & - & $1.1 \%$ & $5.0 \%$ & $1.5 \%$ & $22.3 \%$ \\
\hline 17 & - & - & - & - & - & $23.0 \%$ & - & - & - \\
\hline 18 & - & - & - & - & - & $100 \%$ & - & - & - \\
\hline 20 & $20 \%$ & - & - & - & - & - & - & - & - \\
\hline 28 & - & - & $100 \%$ & $100 \%$ & $11.4 \%$ & - & $10.8 \%$ & - & - \\
\hline 30 & - & - & - & - & - & - & $31.1 \%$ & $100 \%$ & $100 \%$ \\
\hline 32 & - & $100 \%$ & - & - & - & - & - & - & - \\
\hline 40 & $100 \%$ & - & - & - & - & - & - & - & - \\
\hline 44 & - & - & - & - & $100 \%$ & - & $100 \%$ & - & - \\
\hline 45 & - & - & - & - & $1.3 \%$ & - & - & - & - \\
\hline 46 & - & - & - & - & & - & - & - & $37.0 \%$ \\
\hline
\end{tabular}


Fig. 3 DTA/TG curves for $\mathrm{Al}_{2} \mathrm{O}_{3}$ with $3 \mathrm{wt} \%$ of polymer formed from 1- $O$-acryloyl-Dfructose and signals from coupled mass spectrometer showing $m / z$, values characteristic for $\mathrm{Ar}, \mathrm{N}_{2}$ and $\mathrm{O}_{2}$

Fig. 4 DTA/TG curves and $\mathrm{m} / \mathrm{z}$ signals from coupled mass spectrometer $\mathrm{MS}$ for $\mathrm{Al}_{2} \mathrm{O}_{3}$ with $3 \mathrm{wt} \%$ of polymer formed from 1-O-acryloyl-D-fructose

Fig. 5 DTA/TG curves and $\mathrm{m} / \mathrm{z}$ signals from coupled mass spectrometer $\mathrm{MS}$ for $\mathrm{Al}_{2} \mathrm{O}_{3}$ with $20 \mathrm{wt} \%$ of polymer formed from 3-O-acryloyl-D-glucose
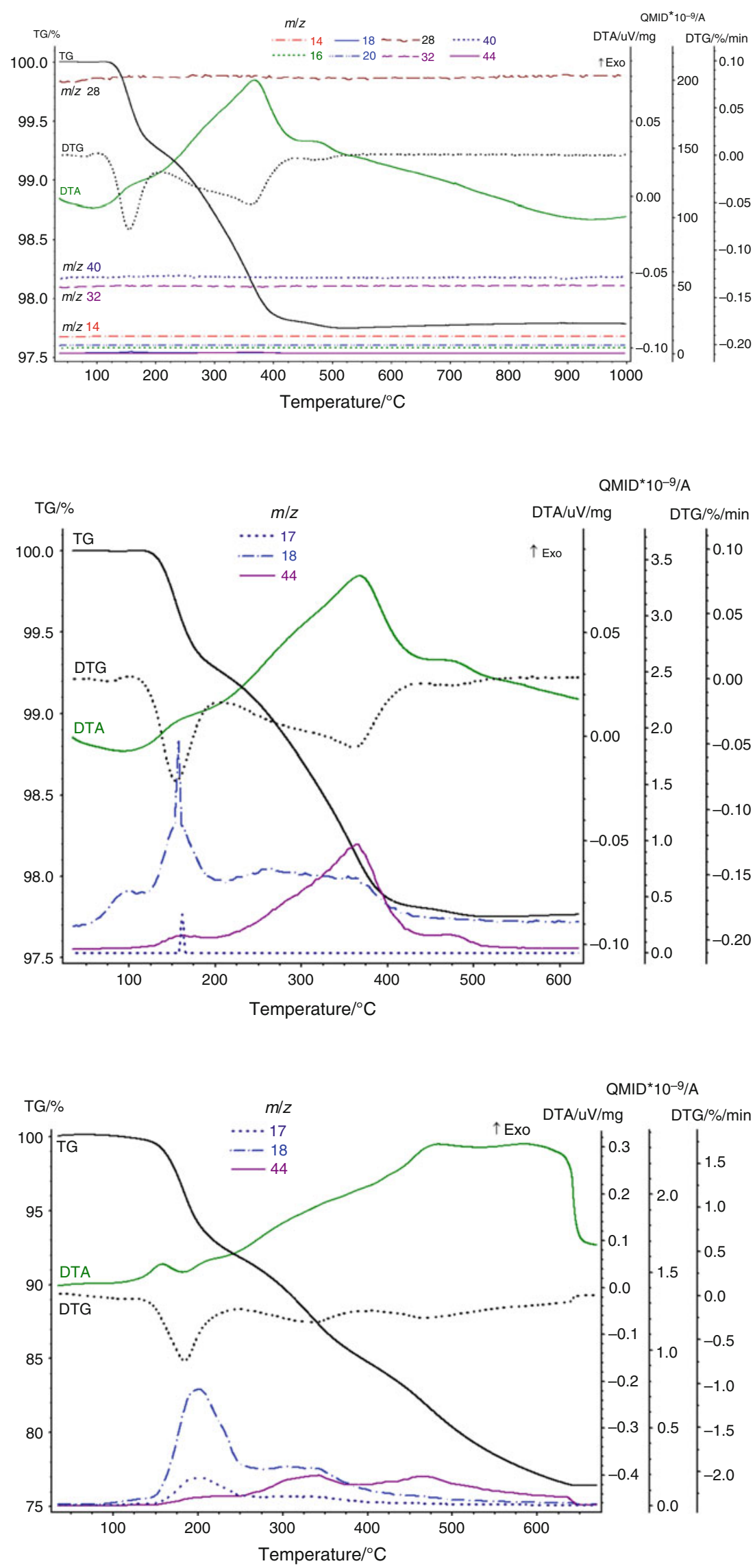
Fig. 6 a DTA/TG curves and $\mathrm{m} / \mathrm{z}$ signals from coupled mass spectrometer $\mathrm{MS}$ for $\mathrm{Al}_{2} \mathrm{O}_{3}$ with $20 \mathrm{wt} \%$ of polymer formed from acrylamide, $\mathbf{b}$ MS curves for $\mathrm{m} / \mathrm{z}$ values 30 and 46

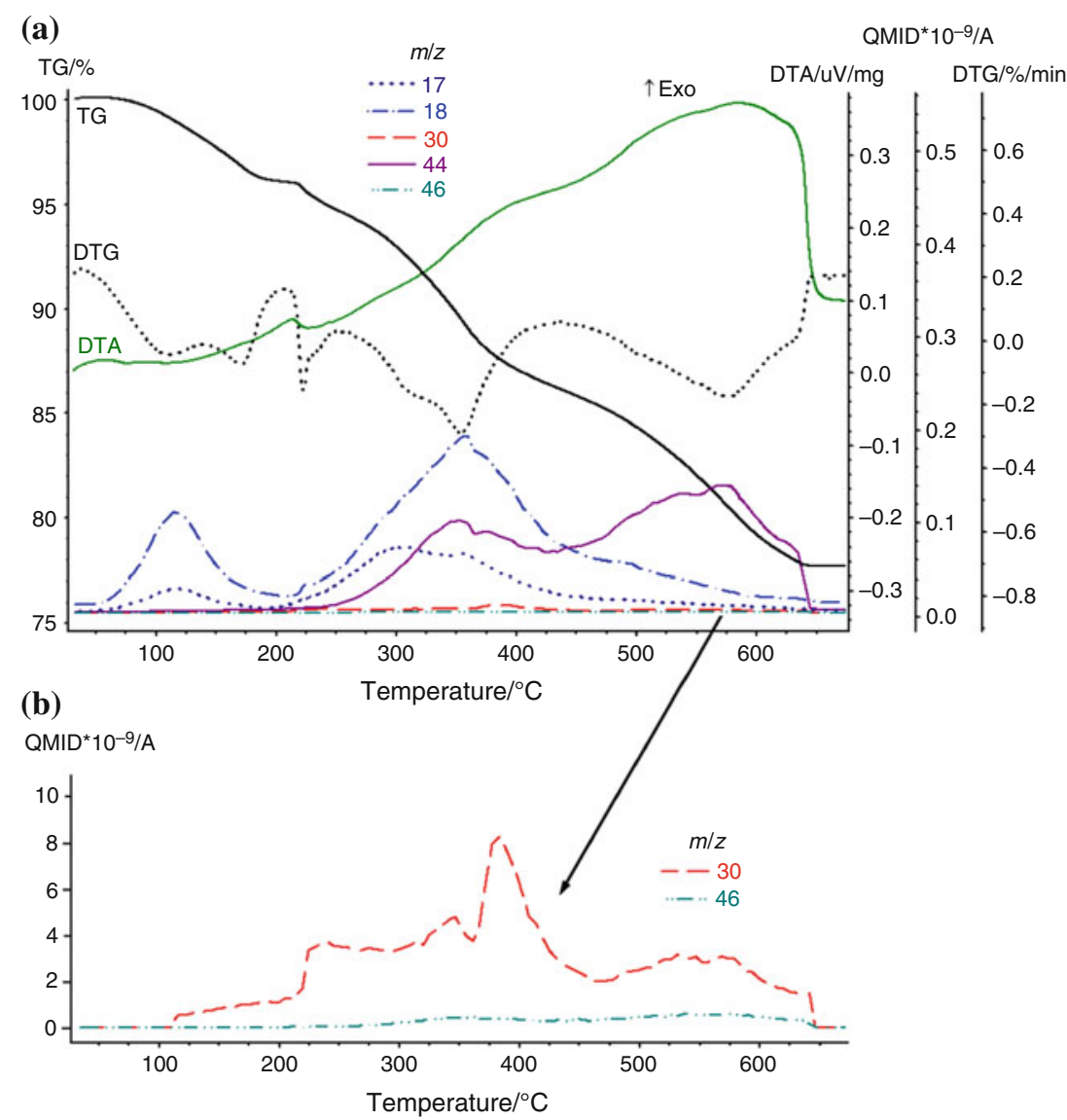

peak 18. The intensity of peak 18 at its maximum in $158^{\circ} \mathrm{C}$ is ca. $1.86 \cdot 10^{-9} \mathrm{~A}$, while the intensity of peak 17 in the same temperature is ca. $0.38 \cdot 10^{-9} \mathrm{~A}$, thus the ratio of peaks $17-18$ is $20.4 \%$. Therefore, in order to identify $\mathrm{H}_{2} \mathrm{O}$ in MS spectra, two parallel curves of $\mathrm{m} / \mathrm{z}$ values 17 and 18 should be present.

On DTA curve one can see also the wide peak with a maximum at $374{ }^{\circ} \mathrm{C}$. This peak is connected with two peaks from MS of $\mathrm{m} / z$ values 18 and 44 . The first one is a broad peak 18 without a clear maximum in the temperature range of $200-425{ }^{\circ} \mathrm{C}$. The second peak 44 with a maximum at $367{ }^{\circ} \mathrm{C}$ corresponds to $\mathrm{CO}_{2}$. These peaks are related to the main stage of decomposition of the polymer. In the polymers obtained from analyzed saccharides derivatives the main polymeric chain comes from acryloyl groups which polymerize in situ. Liufu and et.al. [26] showed that polyacrylates generally decompose in one stage. Finally, the fourth peak visible at DTA occurs at $427{ }^{\circ} \mathrm{C}$, together with MS peak 44 at the same temperature. According to the literature [27, 28] char residue occurs during thermal decomposition of polysaccharides and other polymers. In these studies char residue is oxidized to $\mathrm{CO}_{2}$ due to the constant flow of air, which can be ascribed to the presence of peaks at DTA and MS 44 at temperature $427{ }^{\circ} \mathrm{C}$.
According to the data presented in Table 1, the second peak in mass spectrum characteristic for $\mathrm{CO}_{2}$ is 28 and its intensity equals $11.4 \%$ of the intensity of peak 44 . Nevertheless $m / z$ value 28 is also characteristic for $\mathrm{N}_{2}$ which is the main component of air used in these measurements. The intensity of signal 28 is over 200 times higher than the intensity of signal 44 in its maximum (Fig. 3). Therefore, it is impossible to observe the changes in $\mathrm{m} / \mathrm{z}$ curve 28 which comes from $\mathrm{CO}_{2}$ thus the curve has not been shown in Fig. 4. The mass spectrometer obviously did not register signal 30 characteristic for $\mathrm{NO}_{2}$. Then, the thermal decomposition of polymer from 1-O-acryloyl-D-fructose goes into $\mathrm{H}_{2} \mathrm{O}$ and $\mathrm{CO}_{2}$, which is typical for saccharides in oxidizing atmosphere [29].

Figure 5 shows DTA/TG curves and signals from coupled mass spectrometer MS for sample prepared by gelcasting and composed of $\mathrm{Al}_{2} \mathrm{O}_{3}$ with $20 \mathrm{wt} \%$ of monomer 3-O-acryloyl-D-glucose. In contrary to results presented in Fig. 4 the amount of monomer used in the preparation of this sample was $20 \mathrm{wt} \%$ with respect to the amount of alumina powder. Such increased quantity of monomer is not typical for gelcasting shaping technique but in this research it can more precisely show the type of gases released during thermal decomposition of polymer. The 
Fig. 7 a DTA/TG curves and signals from coupled mass spectrometer MS for $\mathrm{Al}_{2} \mathrm{O}_{3}$ with $20 \mathrm{wt} \%$ of organics $(10 \mathrm{wt} \%$ of polymer formed from 2-hydroxyethyl acrylate and $10 \mathrm{wt} \%$ of cross-linking agent $N, N^{\prime}$-methylenebisacrylamide), b MS curves for $m / z$ values 30 and 46

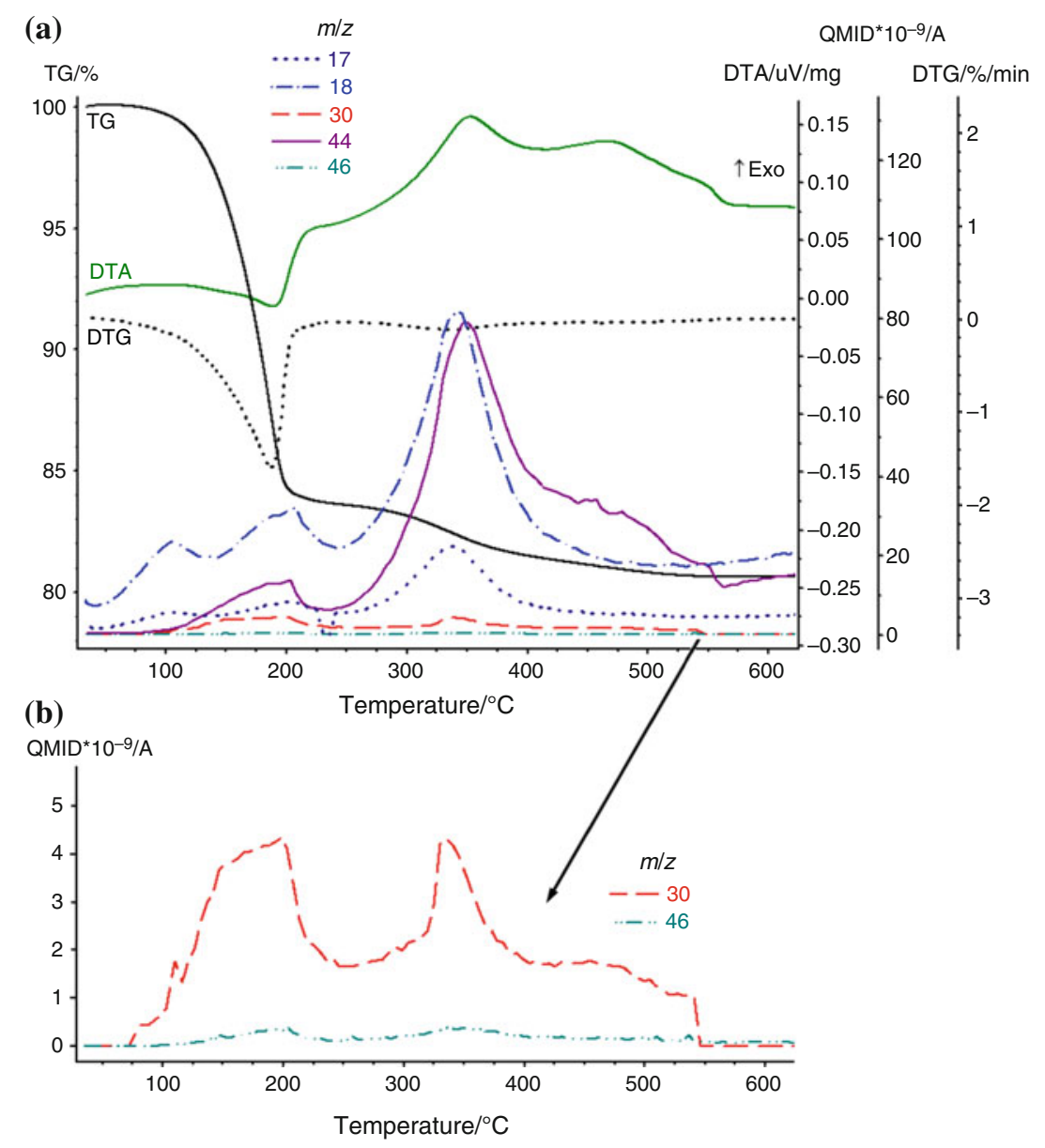

measurement indicates that the total loss of water and decomposition of organic additives occur until ca. $650{ }^{\circ} \mathrm{C}$. The total weight loss according to TG curve is $23.6 \%$, which corresponds to the moisture and organics content. According to TG and DTG curves the loss of bounded water ends at $248{ }^{\circ} \mathrm{C}$. On DTA curve a wide peak with a plateau in temperature range $449-630{ }^{\circ} \mathrm{C}$ is related to the decomposition of organics.

The mass spectrometer recognized three $m / z$ values: 17,18 , and 44 . Values 17 and 18 refer to water, value 44 to carbon dioxide. The first peak maximum for $\mathrm{m} / \mathrm{z}, 17$ and 18 was found at $199{ }^{\circ} \mathrm{C}$ and is related to dehydratation process. The second wide peak for $m / z, 18$ in temperature range $250-410{ }^{\circ} \mathrm{C}$ can be ascribed to decomposition of polymeric rings and oxidation of saccharides molecules. In case of $\mathrm{m} / \mathrm{z} 44$ three peak maxima can be identified, the first one at $210{ }^{\circ} \mathrm{C}$, the second at $341{ }^{\circ} \mathrm{C}$, and the third at $463{ }^{\circ} \mathrm{C}$. The first MS 44 peak can be ascribed to the oxidation of glucose molecules, the second and the third to the decomposition of polymer and oxidation of char residues. The mass spectrometer did not register any other signals which could come from harmful gases.

The direct comparison between the two polymers from 3-O-acryloyl-D-glucose and 1-O-acryloyl-D-fructose would be unprecise, because the amount of polymer in both samples was different. Nevertheless some common features were observed. First of all mass spectrometer in both cases identified only three $\mathrm{m} / \mathrm{z}$ values: 17,18 , and 44 . Second, two main processes occur during decomposition of organics: dehydratation and oxidation reactions of polymeric segments. The differences in the course of DTA and MS curves for both polymers could be caused by differences in molecular structure of monomers. Shen et.al [27] showed that different polysaccharides require different amount of energy for the depolymerisation and the cracking of their monomers, which results in the different position of DTA peaks and TG mass loss stages.

Figure 6 shows DTA/TG curves and signals from coupled mass spectrometer MS for sample prepared by gelcasting and composed of $\mathrm{Al}_{2} \mathrm{O}_{3}$ with $20 \mathrm{wt} \%$ of polymer formed from acrylamide. Acrylamide is a commercial monomer commonly applied in shaping of ceramic powders by gelcasting [30-32]. Similarly to previously described polymers, two main steps of the process can be distinguished; dehydration of bounded water and decomposition of organic substances. Due to TG/DTA curves dehydration ends at $202{ }^{\circ} \mathrm{C}$, then the process of decomposition of polyacrylamide begins and it ends at $650{ }^{\circ} \mathrm{C}$. The total mass loss is $22.3 \%$, which corresponds to the 
content of polymer and moisture in the sample. The DTA curve shows small peak with the maximum at $215^{\circ} \mathrm{C}$ and broad peak with the maximum at $584{ }^{\circ} \mathrm{C}$. Both peaks can be referred to the decomposition of polyacrylamide with the release of firstly $\mathrm{H}_{2} \mathrm{O}$ and secondly $\mathrm{CO}_{2}$. This is confirmed by the results from the mass spectrometer which registered signals of $\mathrm{m} / \mathrm{z}$ values 17,18 and 44 . Curve $\mathrm{m} / \mathrm{z} 18$ has two maxima at 117 and $357^{\circ} \mathrm{C}$, while curve $\mathrm{m} / \mathrm{z} 44$ at 352 and $558{ }^{\circ} \mathrm{C}$. The coarse of DTA curve for polyacryalmide is similar to curve for polymer obtained from 3-O-acryloyl-D-glucose, that is in both curves a small exothermic peak at around $200{ }^{\circ} \mathrm{C}$ and broad peak without a clear maximum in temperature range $450-650{ }^{\circ} \mathrm{C}$ are visible. It means that the dominant process is the decomposition of main polymeric chain formed from acrylic groups. However, for polyacrylamide this process can be more complex due to the presence of amide group.

Mass spectrometer registered also two other signals of $\mathrm{m} / \mathrm{z}$ values 30 and 46, which according to Table 1 refer to $\mathrm{NO}_{2}$. Value 30 can be ascribed also to $\mathrm{NO}$ but in the oxidizing atmosphere in which the experiments have been performed $\mathrm{NO}_{2}$ is much more probable compound to appear. In the applied conditions of measurements it is impossible to recognize possibly occurring $\mathrm{N}_{2} \mathrm{O}$, because the first typical for $\mathrm{N}_{2} \mathrm{O} \mathrm{m} / z$ value 44 is typical also for $\mathrm{CO}_{2}$ and the second $\mathrm{m} / \mathrm{z}$ value 30 can be ascribed also to $\mathrm{NO}_{2}$ and $\mathrm{NO}$. The intensities of signals 30 and 46 are much lower that intensities of signals 18 and 44 (Fig. 6a). This is due to the chemical structure of acrylamide (Fig. 1c) which has one nitrogen atom and three carbon atoms in the molecule, therefore during decomposition more $\mathrm{CO}_{2}$ is formed than $\mathrm{NO}_{2}$. The MS curve for $m / z, 30$ has a maximum at $384{ }^{\circ} \mathrm{C}$, which can be related to decomposition of amide groups, the next peak in temperature range $460-648{ }^{\circ} \mathrm{C}$, together with mentioned $\mathrm{m} / \mathrm{z} 44$ peak with a maximum at $558{ }^{\circ} \mathrm{C}$ can be related to oxidation of $\mathrm{NO}$ and char residue.

Figure 7 shows DTA/TG curves and signals from coupled mass spectrometer MS for sample prepared by gelcasting and composed of $\mathrm{Al}_{2} \mathrm{O}_{3}$ with $10 \mathrm{wt} \%$ of polymer formed from 2-hydroxyethyl acrylate and $10 \mathrm{wt} \%$ of crosslinking agent $N, N^{\prime}$-methylenebisacrylamide. On DTA/TG curves there is a high peak coming from dehydration with the maximum at $188{ }^{\circ} \mathrm{C}$ and then on DTA curve a broad exothermic peak with 4 maxima related to decomposition of organic compounds. The decomposition process ends at ca. $575{ }^{\circ} \mathrm{C}$ which corresponds to the total mass loss $19.4 \%$. However, the main mass loss stage is till $210{ }^{\circ} \mathrm{C}$ (15.8\%) and matches the $\mathrm{m} / \mathrm{z} 30$ wide peak in temperature range $100-224{ }^{\circ} \mathrm{C}$. This indicates that the main processes are dehydration, decomposition, and oxidation of $\mathrm{NH}$ groups in $N, N^{\prime}$-methylenebisacrylamide. The MS registered peaks coming from $\mathrm{H}_{2} \mathrm{O}\left(\mathrm{m} / \mathrm{z}\right.$ values 17 and 18), $\mathrm{CO}_{2}$ $(\mathrm{m} / z$ value 44$)$ and $\mathrm{NO}_{2}(\mathrm{~m} / \mathrm{z}$ values 30 and 46$)$. The peak maxima for $\mathrm{m} / \mathrm{z} 18$ and 44 , together with DTA peak at $352{ }^{\circ} \mathrm{C}$ indicates that the second stage of organic burnout is decomposition of main polymeric chain, followed by oxidation of $\mathrm{NO}$ and char residue.

It must be also mentioned that for all examined specimens the mass spectrometer did not register signals coming from other compounds used in the preparation of samples by the gelcasting method, that is diammonium hydrogen citrate, citric acid, $N, N, N^{\prime}, N^{\prime}$-tetramethylethylenediamine, and ammonium persulfate. This is due to the fact that the content of these substances in the ceramic suspensions equals fraction of percent. Therefore they are not present in the measured sample. On the other hand, the intensities of signals corresponding to these eventually occurring gases could be below the measuring capacity of the mass spectrometer.

Figure 8a shows the microstructure of $\mathrm{Al}_{2} \mathrm{O}_{3}$ green body obtained by gelcasting with the use of monomer 2-hydroxyethyl acrylate. The SEM micrograph shows the polymeric bridges between the alumina particles. The binder connects the ceramic particles and thus allows the mapping of the mold. Then during the sintering process of ceramic green parts the binder must be eliminated so that the polycrystalline material could be formed. The inadequate selection of heating program can cause rapid decomposition of organic substances and thus defects formation in the sintered body.

On the basis of obtained DTA/TG results the heating program for ceramic samples was elaborated. The selection of suitable heating rate in the furnace allows to conduct the processes of thermal decomposition of polymeric binder and sintering of ceramic samples in one stage. The heating program for sample composed of $\mathrm{Al}_{2} \mathrm{O}_{3}$ Nabalox and $3 \mathrm{wt} \%$ of polymer formed from 1-O-acryloyl-D-fructose was determined as follows:

\begin{tabular}{ll}
\hline Heating rate up to $550{ }^{\circ} \mathrm{C}$ & $3{ }^{\circ} \mathrm{C} / \mathrm{min}$ \\
Heating rate in the range $550-1,600{ }^{\circ} \mathrm{C}$ & $5{ }^{\circ} \mathrm{C} / \mathrm{min}$ \\
Sintering at $1,600{ }^{\circ} \mathrm{C}$ & $1 \mathrm{~h}$ \\
Cooling rate up to $30{ }^{\circ} \mathrm{C}$ & $5{ }^{\circ} \mathrm{C} / \mathrm{min}$ \\
\hline
\end{tabular}

The slow increase of temperature in the furnace until $550{ }^{\circ} \mathrm{C}$ was designed to eliminate formation of any defects in the samples, because gases evolving during polymer decomposition can cause cracks and delamination in the sintered body. The sintered undefected ceramic body obtained with the application of heating rate $3{ }^{\circ} \mathrm{C} / \mathrm{min}$ is presented in Fig. 8c. The second sample was also sintered at $1,600{ }^{\circ} \mathrm{C}$ but with a heating rate of $5{ }^{\circ} \mathrm{C} / \mathrm{min}$ in the whole temperature range. This higher heating rate caused accumulation of gases evolved during decomposition of polymers, which resulted in the creation of pores in the 

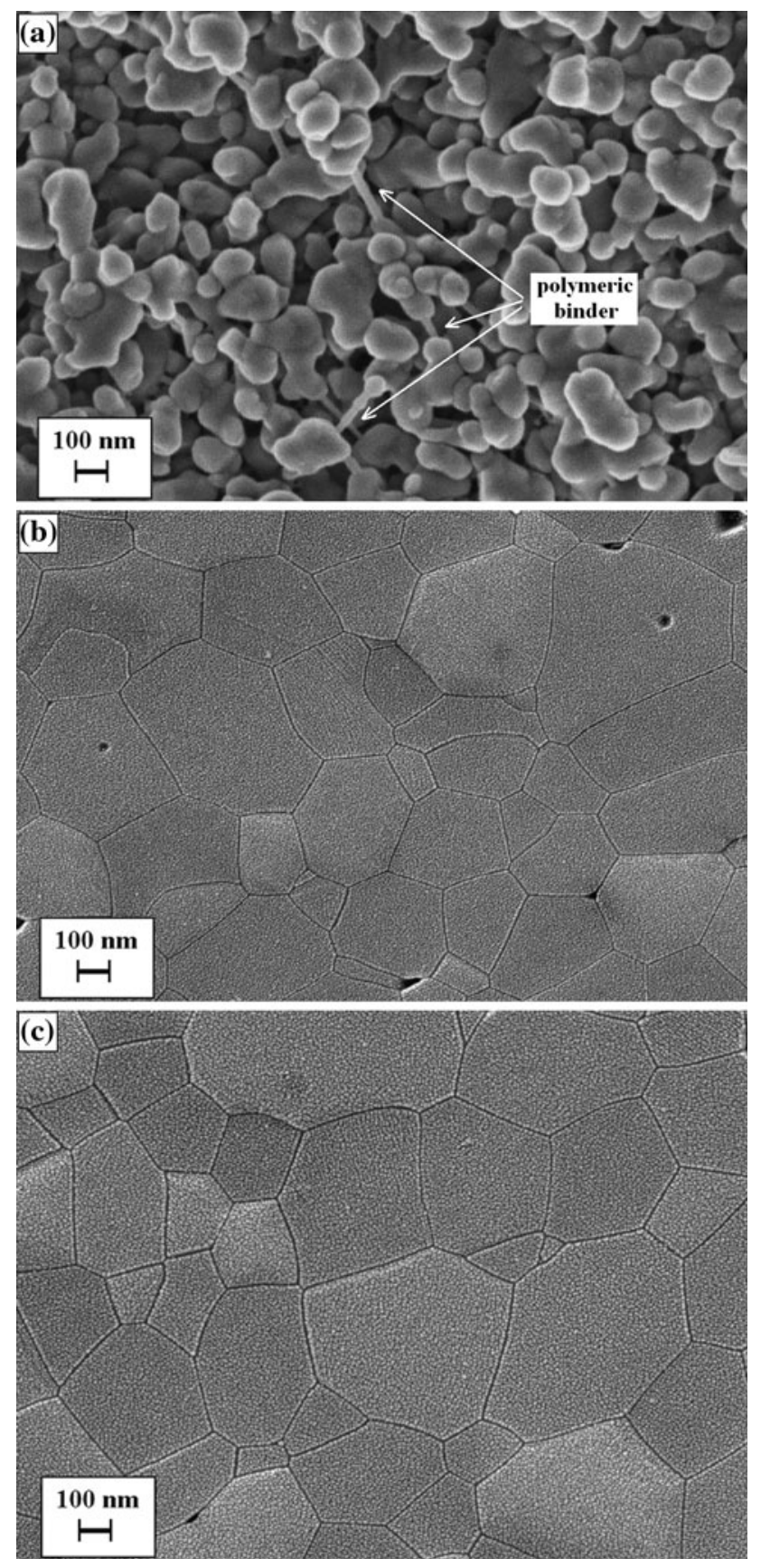

Fig. 8 SEM microstructure of $\mathrm{Al}_{2} \mathrm{O}_{3}$ sample obtained by gelcasting with the use of monomer 2-hydroxyethyl acrylate, a green body, b sintered body obtained with high heating rate during binder decomposition, $\mathbf{c}$ sintered body obtained with properly matched heating rate. The details of heating program are described in the main text

sample as shown in Fig. 8b. The influence of inadequate selection of heating rate on the properties of sintered ceramic bodies is well known and described in literature $[22,33]$. Therefore, it is important to evaluate the optimal sintering program, especially low heating rate below $5{ }^{\circ} \mathrm{C} / \mathrm{min}$ during the process of thermal decomposition of additives. The conducted DTA/TG/MS measurements showed that each of the examined polymers has different characteristics of thermal decomposition, nevertheless the organic part in the ceramic body can be thermally removed until ca. $600{ }^{\circ} \mathrm{C}$. This final temperature is different for each polymer, therefore the heating program in the furnace is individually matched for each binder applied in gelcasting.

\section{Conclusions}

The conducted research allowed to determine the process of thermal decomposition of organic monomers used in shaping of alumina powder by gelcasting method. Mass spectrometer coupled with DTA/TG apparatus is a good tool for a qualitative analysis of gases released during thermal decomposition of various substances. Within the carried out research the evolving gases such as $\mathrm{H}_{2} \mathrm{O}, \mathrm{CO}_{2}$, $\mathrm{NO}_{2}$ have been identified. The results showed that during the thermal decomposition of organic binder resulting from the polymerization of synthesized by authors monomers 1-O-acryloyl-D-fructose and 3- $O$-acryloyl-D-glucose no harmful gases are released to the atmosphere. These substances decompose with the release of $\mathrm{H}_{2} \mathrm{O}$ and $\mathrm{CO}_{2}$. While the application of commercial monomers such as acrylamide and cross-linking substances e.g., $N, N^{\prime}$-methylenebisacrylamide results in releasing of harmful $\mathrm{NO}_{\mathrm{x}}$.

The measurements showed differences in stages of thermal decomposition of analyzed substances, nevertheless the most important information for ceramic technology are the terminal temperature of organics decomposition and types of gases released during the process. The DTA/TG measurements allowed to elaborate the appropriate heating program for sintering of ceramic samples, so that the resulting polycrystalline body was without any microstructural defects. In accordance to thermal analysis, decomposition of analyzed binders ends at ca. $600{ }^{\circ} \mathrm{C}$ but have to be individually examined. Nevertheless, low heating rate of $3{ }^{\circ} \mathrm{C} / \mathrm{min}$ at this first stage of sintering is favorable in ceramic processing.

Acknowledgements This study has been supported by the Faculty of Chemistry of Warsaw University of Technology and the Ministry of Science and Higher Education of Poland (Grants No. N R05 001506 and IP2011 002171).

Open Access This article is distributed under the terms of the Creative Commons Attribution License which permits any use, distribution, and reproduction in any medium, provided the original author(s) and the source are credited.

\section{References}

1. Young AC, Omatete OO, Janey MA, Menchhofer PA. Gelcasting of alumina. J Am Ceram Soc. 1991;74(3):612-8. 
2. Santacruz I, Nieto MI, Binner J, Moreno R. Gel casting of aqueous suspensions of $\mathrm{BaTiO}_{3}$ nanopowders. Ceram Int. 2009;35:321-6.

3. Chabert F, Dunstan DE, Franks GV. Cross-linked poly vinyl alcohol as a binder for gelcasting and green machining. $\mathrm{J}$ Am Ceram Soc. 2008;91(10):3138-46.

4. Uchikoshi T, Suzuki T, Okuyama H, Sakka Y, Nicholson P. Electrophoretic deposition of alumina suspension in a strong magnetic field. J Eur Ceram Soc. 2004;24:225-9.

5. Suzuki T, Uchikoshi T, Okuyama H, Sakka Y, Hiraga K. Mechanical properties of textured, multilayered alumina produced using electrophoretic deposition in a strong magnetic field. J Eur Ceram Soc. 2006;26:661-5.

6. Graule TJ, Baader FH, Gauckler LJ. Shaping of ceramic green compacts direct from suspensions by enzyme catalyzed reactions. Ceram Forum Int. 1994;71:317-23.

7. Gauckler L, Graule T, Baader F. Ceramic forming using enzyme catalyzed reactions. Mater Chem Phys. 1999;61:78-102.

8. Annola K, Keski-Rahkonen P, Vahakangas K, Lehtonen M. Simultaneous determination of acrylamide, its metabolite glycidamide and antipyrine in human placental perfusion fluid and placental tissue by liquid chromatography-electrospray tandem mass spectrometry. J Chromatogr B. 2008;876:191-7.

9. Ma LG, Huang Y, Yang JL, Le HR, Sun Y. Control of the inner stresses in ceramic green bodies formed by gelcasting. Ceram Int. 2006;32:93-8.

10. Potoczek M. A catalytic effect of alumina grains onto polymerization rate of methacrylamide-based gelcasting system. Ceram Int. 2006;32:739-44.

11. Padilla S, Garcia-Carrodeguas A, Vallet-Regi M. Hydroxyapatite suspensions as precursors of pieces obtained by gelcasting method. J Eur Ceram Soc. 2004;24:2223-32.

12. Prabhakaran K, Lakra J, Beigh MO, Gokhale NM, Sharma SC, Lal R. Sinterable $\mathrm{La}_{0.8} \mathrm{Sr}_{0.2} \mathrm{CrO}_{3}$ and $\mathrm{La}_{0.7} \mathrm{Ca}_{0.3} \mathrm{CrO}_{3}$ powders by sucrose combustion synthesis. J Mater Sci. 2006;41:6300-4.

13. Schilling $\mathrm{CH}$, Bellman RA, Smith RM, Goel H. Plasticizing aqueous suspension of concentrated alumina with maltodextrin sugar. J Am Ceram Soc. 1999;82(1):57-66.

14. Shortridge PG, Harris PJ, Bradshaw DJ, Koopal LK. The effect of chemical composition and molecular weight of polysaccharide depressants on the flotation of talc. Int J Miner Process. 2000;59: 215-24.

15. Bednarek P, Szafran M, Sakka Y, Mizerski T. Gelcasting of alumina with a new monomer synthesized from glucose. J Eur Ceram Soc. 2010;30:1795-801.

16. Falkowski P, Bednarek P, Danelska A, Mizerski T, Szafran M. Application of monosaccharides derivatives in colloidal processing. J Eur Ceram Soc. 2010;30:2805-11.

17. Bednarek P, Szafran M, Mizerski T. Saccharides derivatives in shaping of ceramic powders-new monomers and dispersants. Adv Sci Technol. 2010;60:169-74.
18. Szafran M, Jach K, Tomaszewska-Grzeda A, Rokicki G. Utilisation of enzymatic reactions in $\mathrm{Al}_{2} \mathrm{O}_{3}$ powder molding process. J Thermal Anal Calorim. 2003;74:639-46.

19. Szafran M, Wisniewski P, Rokicki G. Effect of glass transition temperature of polymeric binders on properties ceramic materials. J Thermal Anal Calorim. 2004;77:319-27.

20. Leszczynska A, Pielichowski K. Application of thermal analysis methods for characterization of polymer/montmorillonite nanocomposites. J Thermal Anal Calorim. 2008;93(3):677-87.

21. Shaw HM, Edirisinghe MJ. Shrinkage and particle packing during removal of organic vehicle from ceramics injection mouldings. J Eur Ceram Soc. 1995;15:109-16.

22. Liu W, Jiang B, Zhang W, Li J, Zhou J, Zhang D, Pan Y, Guo J. Influence of heating rate on optical properties of Nd:YAG laser ceramic. Ceram Int. 2010;36:2197-201.

23. Alcolea A, Ibarra I, Caparros A, Rodriguez R. Study of the MS response by TG-MS in an acid mine drainage efflorescence. J Thermal Anal Calorim. 2010;101:1161-5.

24. Etienne S, Becker C, Ruch D, Germain A, Calberg C. Synergetic effect of poly(vinyl butyral) and calcium carbonate on thermal stability of poly(vinyl chloride) nanocomposites investigated by TG-FTIR-MS. J Thermal Anal Calorim. 2010;100:667-77.

25. Masset P, Poinso JY, Poignet JC. TG/DTA/MS study of the thermal decomposition of $\mathrm{FeSO}_{4} \cdot 6 \mathrm{H}_{2} \mathrm{O}$. J Thermal Anal Calorim. 2006;83(2):457-62.

26. Liufu SC, Xiao HN, Li YP. Thermal analysis and degradation mechanism of polyacrylate/ZnO nanocomposites. Polym Degrad Stab. 2005;87:103-10.

27. Shen DK, Gu S, Bridgwater AV. The thermal performance of the polysaccharides extracted from hardwood: cellulose and hemicellulose. Carbohydr Polym. 2010;82:39-45.

28. Potoczek M, Heneczkowski M, Oleksy M. A new polyurethane binder providing high green strength of dry-pressed alumina. Ceram Int. 2003;29:259-64.

29. Collins PM. Monosaccharides: their chemistry and their roles in natural products. Chichester: Wiley; 1995.

30. Janney MA, Nunn SD, Walls CA, Omatete OO, Ogle RB, Kirby GH, McMillan AD (1998) In: Dekker M (ed) Gelcasting, the handbook of ceramic engineering.

31. Maa J, Xiea Z, Miaoa H, Huanga Y, Chengb Y. Gelcasting of ceramic suspension in acrylamide/polyethylene glycol systems. Ceram Int. 2002;28:859-64.

32. Yichen H, Zhongjian W, Jianying L. Study on the gel casting of fused silica glass. J Non Cryst Sol. 2008;354:1285-9.

33. Lei W, Lu WZ, Zhu JH, Ye X. Effects of heating rate on microstructures and microwave dielectric properties of $(1-x) \mathrm{ZnAl}_{2} \mathrm{O}_{4-x} \mathrm{TiO}_{2} \quad(x=0.21) \quad$ ceramics. Ceram Int. 2009;35:277-80. 